http://jmscr.igmpublication.org/home/ ISSN (e)-2347-176x ISSN (p) 2455-0450

crossref DOI: https://dx.doi.org/10.18535/jmscr/v7i12.66

\title{
Pilonidal Sinus Presenting Off the Midline in Gluteal Region- A Case Report Authors
}

\author{
Talib Hussain ${ }^{1 *}$, Sanjay K Bhasin ${ }^{2}$, Sanjay Sharma ${ }^{3}$, Abhinav Mani ${ }^{4}$ \\ ${ }^{1}$ Lecturer, ${ }^{2}$ Professor, ${ }^{3}$ Assistant professor, ${ }^{4}$ Lecturer \\ Department of Surgery, Government Medical College Jammu, Jammu and Kashmir, India \\ *Corresponding Author \\ Talib Hussain \\ Medical Enclave, Opposite K C Cinema, Bakshi Nagar, Jammu, 180001, Jammu and Kashmir, India
}

\begin{abstract}
Pilonidal disease is considered to be an acquired condition caused by hair invading the skin. Though it can affect many parts of body, such as hands, umbilicus, axillae and external genitalia, but most commonly it occurs in the gluteal cleft or sacrococcygeal region in the midline. Here we report a case of pilonidal sinus presenting off the midline in gluteal region.
\end{abstract}

Keywords: Pilonidal disease, incision and drainage, cleft lift, limberg flap, karydakis flap.

\section{Introduction}

Pilonidal disease is a common condition that affects many patients. Initially it was thought to be a congenital condition but various theories have provided explanation in support of acquired disorder The clinical presentation can range from asymptomatic small midline pit in gluteal cleft to an obvious, painful abscess or complex sinus tracts. Treatment options range from non operative modalities, simple incision and drainage of abscesses, to wide excision with extensive reconstructive procedures for complex disease. The sacrococcygeal pilonidal disease usually presents in the midline, but here we are reporting a case of pilonidal sinus presenting off the midline in left gluteal region.

\section{Case Report}

48 yrs old male presented to hospital with complaints of swelling over left buttock from last 3 months. History of ATT intake 4 yrs back for a period of 6 months for cutaneous tuberculosis (scrofuloderma right scapular region).
General physical examination was unremarkable. Local examination revealed a single, non-tender, firm, oval swelling of about $3.5 \times 3 \mathrm{~cm}$ in size in upper part of left gluteal region about $3 \mathrm{~cm}$ away from gluteal cleft. The overlying skin showed multiple pigmented spots. A small pit was present in the gluteal cleft without any discharge/ redness/swelling, and the probing was negative (Figure 1).

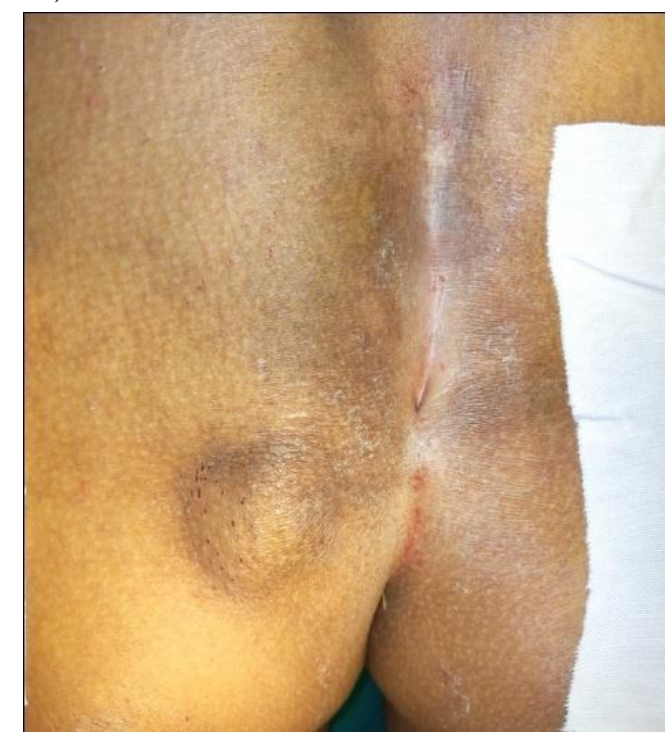

Figure 1. Swelling over left gluteal region with an asymptomatic pit in midline 


\section{JMSCR Vol||07||Issue ||12||Page 365-368||December}

Investigations revealed blood group of $\mathrm{B}+\mathrm{ve}$. $\mathrm{CBC}$, RFT, LFT, PTI were normal. FNAC of swelling suggestive of foreign body granuloma. Excision of swelling was planned. Eliptical skin incision made, deepened to subcutaneous tissue. A tuft of hair came out which had attained a shape of ear ring (Figure 2).

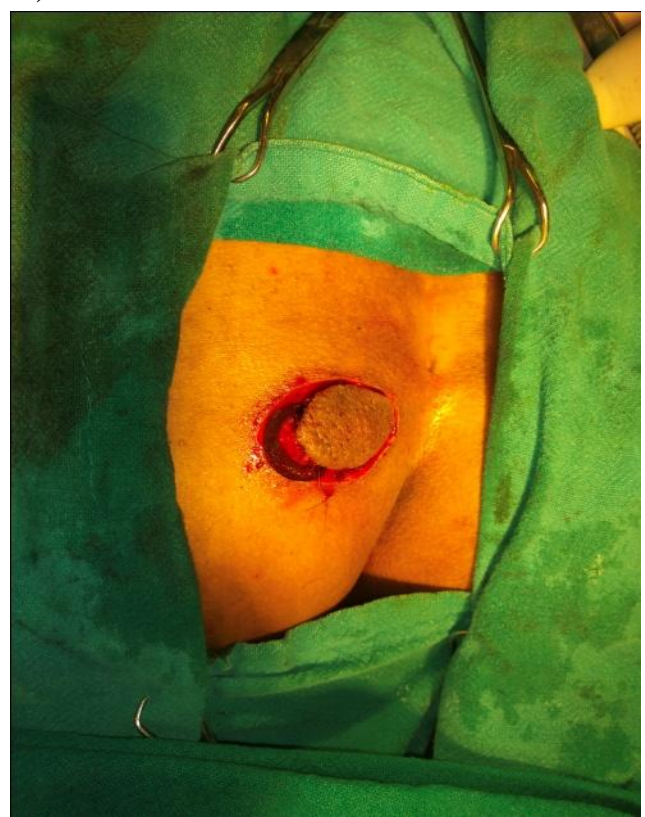

Figure 2. Ear ring shaped tuft of hair.

After careful dissection a sinus tract identified, probed and blue dye was injected. The probe came out through the pit in gluteal cleft (Figure 3).

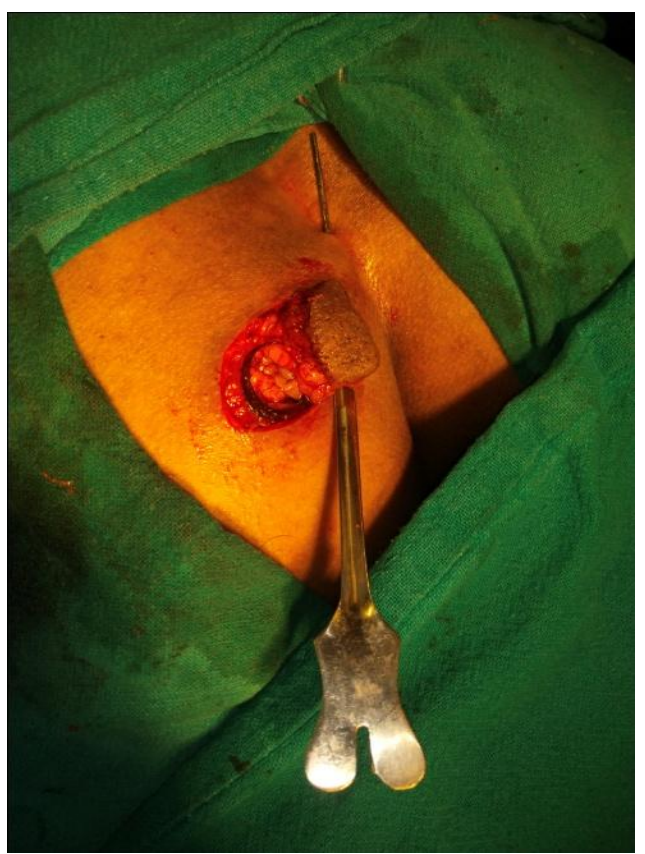

Figure 3 Sinus tract communicating with gluteal cleft pit.
The entire sinus tract dissected from underlying tissues (Figure 4) and then excised.

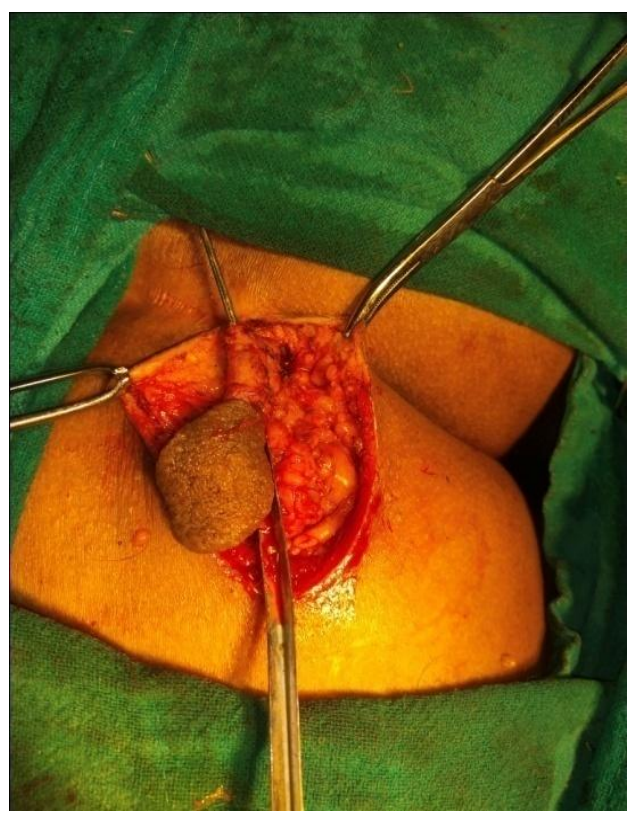

Figure 4. Sinus tract being dissected from the surrounding tissues

After thorough irrigation, suction drain kept in, fat closed using vicryl 2-0 and skin closed using silk 20 (Figure 5).

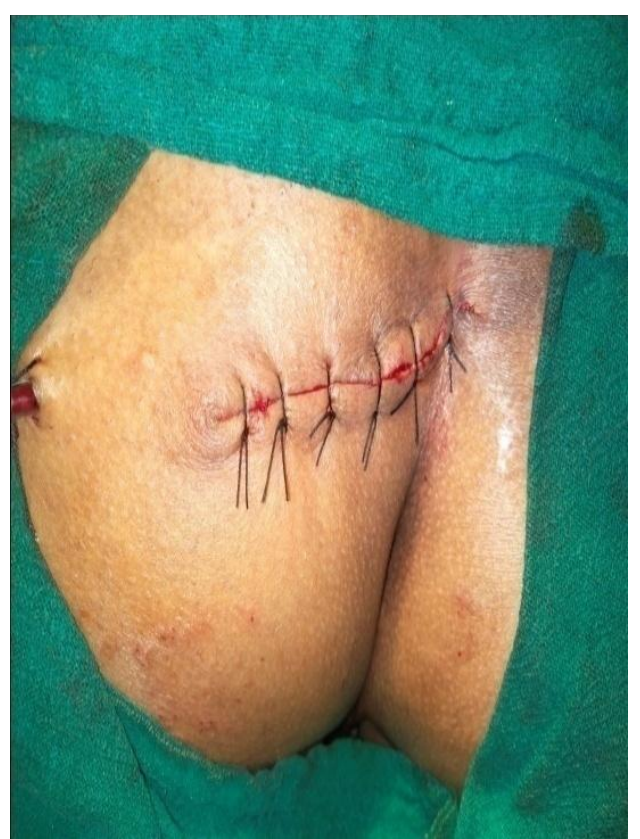

Figure 5. Primary closure of wound in two layers over a suction drain.

The specimen was sent for histopathological examination (Figure 6). 


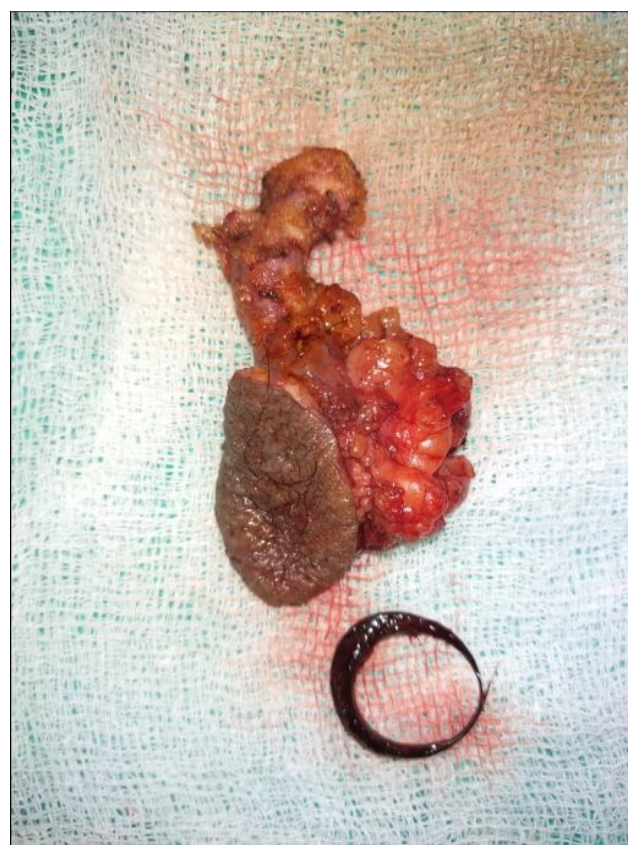

Figure 6 Excised specimen comprised of skin, entire sinus tract and tuft of hair.

\section{Discussion}

The term pilonidal is derived from the latin words for hair (pilas) and nest (nidus) ${ }^{1}$. For many years it was thought to be a congenital condition, but the current explanation is that of an acquired condition caused by hair invading the skin at natal cleft ${ }^{2}$. Due to suction effect of gluteal movement and gluteal cleft friction ${ }^{3}$, the hair is drawn into the pilonidal cavity which can lead to folliculitis and small subdermal abscesses which coalesce to form large abscess cavity.

The pilonidal disease can present in one of three ways: acute abscess, sinus tract, or complex disease with chronic recurring abscesses and extensive branching sinus tracts. Squamous cell carcinoma can develop in long standing pilonidal disease ${ }^{4}$.

The differential diagnosis of sacrococcygeal pilonidal disease includes furuncle, hidradenitis suppurativa, fistula-in-ano, perianal abscess, sacrococcygeal osteomyelitis, syphilis, tuberculosis and actinomycosis.

Histopathology demonstrates foreign body giant cells associated with hair shafts within a background of chronic granulation tissue lining the abscess cavities and sinus tracts.

Treatment of pilonidal disease depends on the clinical presentation and can range from nonoperative treatment to extensive reconstructive procedures. Medical management includes maintaining good perineal hygeine, meticulous hair control by shaving or laser depilation ${ }^{5}$, phenol injection ${ }^{6}$, fibrin glue injection and antibiotics.

Surgical management includes incision and drainage alone, incision and drainage with marsupialization or saucerization ${ }^{7}$, midline follicle excision and lateral drainage (Bascom I operation), excision with or without primary closure and excision with closure using various reconstructive flaps. Reconstructive flaps should be reserved for complex pilonidal disease i.e., recurrent cases, chronic draining sinuses and nonhealing wounds. Incidence of recurrence following primary surgical treatment range from $3 \%$ to $40 \%^{8}$. Reconstructive procedures include rhomboid excision and limberg flap ${ }^{9}, \quad$ karydakis flap $^{10}$, Z-plasty, V-Y fasciocutaneous flap, gluteal myocutaneous flap and cleft lift (Bascom II) operation ${ }^{11^{-}}{ }^{12}$. The rate of recurrence following reconstructive procedures is in the range of $2 \%$ to $11 \%$.

\section{Conclusion}

Differential diagnosis of pilonidal disease should always be considered in a swelling located off the natal cleft or in gluteal region.

\section{References}

1. Bendewald FP, Cima RR: Pilonidal disease. Clin Colon Rectal Surg 20:86, 2007.

2. Patey D, Scarff RW: The hair of the pilonidal sinus. Lancet 268:772, 1955.

3. Bascom $\mathrm{J}$, : Pilonidal disease: origin from follicles of hair and results of follicle removal as treatment. Surgery 87:567, 1980.

4. Davis KA, Mock CN, Versaci A, et al: Malignant degeneration of pilonidal cysts. Am Surg 60:200, 1994.

5. Odili J, Gault D: Laser depilation of the natal cleft-an aid to healing the pilonidal sinus. Ann R Coll Surg Engl 84:29, 2002.

6. Dogru O, Camci C, Aygen E, et al: Pilonidal sinus treated with crystallized phenol: An 
eight year experience. Dis Colon Rectum 47:1934, 2004.

7. Karakayali F, Karagulle E, Karabulut Z, et al: Unroofing and marsupialization versus rhomboid excision and limberg flap in pilonidal disease: A prospective, randomized, clinical trial. Dis Colon Rectum 52:496, 2009.

8. Velasco AL, Dunlap WW: Pilonidal disease and hidradenitis. Surg Clin N Am 9:689, 2009.

9. Daphan C, Tekelioglu MH, Syilgan C, et al: Limberg flap repair for pilonidal sinus disease. Dis Colon Rectum 47:233, 2004.

10. Can MF, Sevinc MM, Yilmaz N: Comparison of karydakis flap reconstruction versus primary midline closure in sacrococcygeal pilonidal disease: Results of 200 military service members. Surg Today 39:580, 2009.

11. Senapati A, Cripps NP, Flashman K, et al: Cleft closure for the treatment of pilonidal sinus disease. Colorectal Dis 13:333, 2011.

12. Tezel E, Bostanci H, Anadol AZ, et al. Cleft lift procedure for sacrococcygeal pilonidal disease. Dis Colon Rectum 52:135, 2009. 